\title{
Leveraging resistance to change and the skunk works model of innovation
}

\author{
Andrea Fosfuri ${ }^{a, *}$, Thomas Rønde ${ }^{b, c, d, e}$ \\ a Universidad Carlos III de Madrid, Getafe 28903, Spain \\ b Centre Economic Policy Research, London EC1V ODG, UK \\ c Department of Innovation and Organizational Economics, Copenhagen Business School, 2000 Frederiksberg, Denmark \\ d Centre for Economic and Business Research, Copenhagen Business School, 2000 Frederiksberg, Denmark \\ e Centre for European Economic Research (ZEW), 68131 Mannheim, Germany
}

\section{A R T I C L E I N F O}

\section{Article history:}

Received 14 August 2007

Received in revised form 4 May 2009

Accepted 6 May 2009

Available online 20 May 2009

JEL classification:

L2

M12

M54

O31

032

Keywords:

Resistance to change

Innovation

Skunk works model

Contest

\begin{abstract}
A B S T R A C T
We study a situation in which an R\&D department promotes the introduction of an innovation that results in costly re-adjustments for production workers. In response, the production department tries to resist change by improving the existing technology. Resistance to change triggers competition between departments, which, in turn, spurs effort. We show that firms balancing the strengths of the two departments perform better. As a negative effect, resistance to change might distort the R\&D department's effort away from radical innovations. The firm can solve this problem by implementing the so-called skunk works model of innovation where the R\&D department is isolated from the rest of the organization. Several implications for managing resistance to change and for the optimal design of $R \& D$ activities are derived.
\end{abstract}

\section{Introduction}

Innovation is one of the main drivers of a firm's competitive advantage. Innovation may, however, challenge the statusquo, and force change and adjustment within the organization (Henderson and Clark, 1990; Henderson, 1993). Change is costly, not only for the firm as a whole, but also for each of its individual members. For instance, Morrill (1991) identifies several potential sources of costs: loss of power and prestige, need to retrain and relearn, changing definition of success, fear of technology, etc. In an attempt to avoid these costs, the employees of the firm may sometimes react to change by fighting it back rather than adapting to it.

In large corporations, this resistance to change can develop into potential conflicts between functions or departments, insofar as an innovation championed by one function inflicts some costs upon another function. Interdepartmental conflicts have been analyzed extensively in the new product development (NPD) literature (e.g., Luo et al., 2006). An established

* Corresponding author at: Universidad Carlos III de Madrid, Department of Business Administration, Calle Madrid 126, 28903 Getafe, Madrid, Spain. Tel.: +34916249351; fax: +34916249607.

E-mail addresses: andrea.fosfuri@uc3m.es (A. Fosfuri), thr.ino@cbs.dk (T. Rønde). 
wisdom argues that conflicts are counter-productive because they disrupt teamwork and harmony within the organization (Griffin and Hauser, 1996). However, a growing number of studies has shown that "a healthy dose of conflict also plays an important role in fostering innovation" (Dyer and Song, 1998; Xie et al., 1998). While little systematic evidence exists for how pervasive interdepartmental conflicts due to innovation and resistance to change are, the aforementioned debate within the NPD literature suggests that the phenomenon is of practical relevance and worthy of deeper consideration (Birkinshaw and Lingblad, 2005).

How should a firm manage resistance to change and the resulting conflict between functions? To address this question, we build a game theoretical model where the implementation of a successful innovation, backed by an R\&D department, results in costly changes for a production department. In response, the production department tries to improve the current technology in an attempt to convince the management not to implement the innovation. The two departments are, in other words, involved in a contest of technologies. ${ }^{1}$ As an example of the type of situation we have in mind, Foster (1986) describes the case of DuPont and its decision in the 1950s to move from the established nylon technology to the new polyester technology for the production of car tires. Behind the decision there was a conflict between production engineers at the nylon plant and researchers supporting the new technology. The production engineers managed to push the nylon technology to the limits, and provided sufficient evidence to convince the management that the nylon technology would remain competitive. The polyester technology was eventually shelved.

We show that organizations with greater resistance to change, i.e. firms whose production departments face larger costs of re-adjustment, exhibit a lower probability of introducing a new technology. However, this is not always profit reducing for the firm as a whole. Indeed, it is shown that firms with highly motivated and productive R\&D departments might benefit from a stronger resistance to change. By contrast, firms whose R\&D departments are weak or badly motivated suffer from stronger resistance to change. More in general, our findings suggest that firms that maintain a balance of powers between the two departments outperform firms where one department largely dominates the other. ${ }^{2}$

Although our analysis stresses the positive effects of internal competition, we argue in the second part of the paper that (the threat of) internal competition might entail important costs for the firm. In particular, the prospect of a costly contest of technologies might push the R\&D department towards low risk, incremental projects that entail low adaptation costs for the production department. Such incremental innovations meet much less internal resistance than radical innovations that require the production department to undertake more costly changes. Thus, the R\&D department refrains from investigating more path-breaking research trajectories at the detriment of long-run firm profits.

We analyze an organizational solution to this problem, known as the skunk works model of innovation, which consists in isolating the team of researchers from the influence of the rest of the organization. ${ }^{3}$ The skunk works model of innovation has received lots of attention from management scholars and has been implemented by many large technology firms, such as IBM, Siemens and Intel, but we are not aware of any formal economic model that attempts to pin down the virtues of this organizational solution. We show that adopting the skunk works model of innovation can induce the R\&D department to choose a radical research trajectory in situations where an integrated R\&D department would have chosen an incremental trajectory to avoid the competition with the production department.

This paper is related to several bodies of literature both in economics and management. Resistance to change is a source of inertia in our model both because it reduces the probability that new technologies are implemented and because it distorts the search process of the R\&D department towards an incremental research trajectory. Scholars in evolutionary economics have investigated extensively the sources of inertia within organizations. Nelson and Winter (1982) and Dosi (1982), among others, have stressed how scientists and engineers tend to myopically focus on existing technological trajectories and paradigms, overlooking opportunities lying outside their search range. While the latter is undoubtedly an important motivation behind organizational inertia, our model provides a complementary explanation based on interdepartmental conflict as discussed above.

The adoption of a new technology is a decision that has important redistribution effects within the organization. The economics literature has argued that such decisions are subject to influence activities by the involved parties, i.e. efforts aimed at affecting the decision maker (Meyer et al., 1992; Milgrom, 1988; Milgrom and Roberts, 1988). Such efforts distort resources from more productive uses, slow down the decision making process, and sometimes prevent organizational changes altogether (Schaefer, 1998). Our approach can be thought of as representing a different time horizon. Shortly before the management decides which technology to use, the performances of the technologies are more or less given. The departments will therefore spend resources trying to promote their preferred technology by presenting it well, buttering up decision makers, etc. This is the situation captured by influence activity models. By contrast, we argue that there is an incentive earlier

\footnotetext{
${ }^{1}$ Contests are situations in which the participants expend money or effort to increase their chances of winning a prize. Examples include rent-seeking and lobbying situations, tournaments, arms races, political campaigns, athletic contests, patent races and procurement of innovations (Taylor, 1997; Che and Gale, 2003; Ganuza and Hauk, 2006).

2 Evidence consistent with the notion that this type of organizational competition spurs innovation can be found in Ginn and Rubenstein (1986). They study 61 new product introductions in a major chemical company. They show that product introductions leading to more intense competition, measured by how incompatible the R\&D department's and the production department's goals are, tend to be more successful than product introductions causing less competition.

3 A windowless facility built by Lockheed at the airport of Burbank, California, during the Cold War was known as the skunk works. There, secret military projects were developed. The term is borrowed from Al Capp's comic strip Li'l Abner, which was popular in the 1940 s.
} 
in the game to improve the technologies to have as strong a case as possible should the competition between departments take place. We focus here on this long-run effect, but this is, of course, not to say that influence activities do not exist or are irrelevant.

Organizational scholars have widely investigated the tension between the exploration of new alternatives and the exploitation of current capabilities (Levinthal and March, 1993; March, 1991) by employing simulation models based on routine adaptation and learning (Rivkin and Siggelkow, 2003). Exploitation refers to achieving maximal profits in the current situation whereas exploration refers to the process of searching for new opportunities. In our model, the production department is involved in exploitative activities, while the R\&D department explores new technological possibilities. Although we leave many of the subtleties in the background, we provide a different, incentive-based view of such a tension. Similarly to this literature, we show that firms are well-advised in trying to balance explorative and exploitative activities. However, we also find that exploitation might, under certain conditions, increase exploration by exposing the R\&D department to tougher internal competition.

Besides the already mentioned works, our analysis is related to two papers by Rotemberg and Saloner. In Rotemberg and Saloner (1995), using a quite different model, the authors study the conflict between the sales and the production departments, with the former wanting a broad product line and the latter wanting long production lines. The firm can potentially benefit from the conflict, because the two departments present valuable information concerning costs to defend their respective positions. Nevertheless, as their emphasis is on cost revelation, they do not study questions related to innovation policies, which is our main interest here. Rotemberg and Saloner (2000) analyze competition between two R\&D teams inside a firm. Again, the focus of their paper is quite different from ours. Rotemberg and Saloner study how hiring a biased (visionary) CEO can induce higher efforts by the teams, but they do not look at issues such as, e.g., the skunk works model of innovation and the tension between exploitation and exploration, which constitute the main contribution of our work.

The rest of the paper is organized as follows: the next section describes the basic model that is then solved and discussed in Section 3. In the basic model the possibility of using contracts to induce effort from the departments is assumed away. It illustrates, however, the driving forces behind our findings and provides interesting insights on how interdepartmental conflicts within an organization should be managed. Section 4 extends the basic framework by allowing the R\&D department to choose the type of innovation to pursue (incremental vs. radical). It addresses the following question: what can the management do if the conflict between departments is so tough that the R\&D department shies away from a radical research trajectory? The solution proposed is the skunk works model of innovation, which is shown to solve this problem provided that researchers have sufficient intrinsic motivation to work on a radical research trajectory. In Section 5 we analyze and discuss alternative contractual assumptions, and show that our findings remain qualitatively unchanged as long as contractual possibilities are incomplete. Section 6 summarizes our results and discusses managerial implications. Appendix A contains formal proofs and technical material.

\section{The basic model}

Our firm is composed by three risk-neutral agents: a production unit (PU), a research unit (RU) and a management unit (MU), which we describe in more detail below. Our framework captures better the reality of large firms where a clear distinction between the RU and the PU exists. ${ }^{4}$ The firm is actually employing a standard technology to produce a given product, which results in a profit of $\pi_{1}=0$ if no further improvements are made.

\subsection{The research unit}

The RU expends unobservable creative effort, $e_{R}$, that probabilistically generates a "new technology", which could either be a new product or a new process. The creative effort results in a new technology of value $\Delta_{R}$ with probability $p$ where $\Delta_{R}=\gamma e_{R}$, and $\gamma>0$. With the complementary probability, $1-p$, the effort is fruitless. The cost of effort is $c\left(e_{R}\right)=e_{R}$. The RU receives a reward $B$ if the new technology is adopted and 0 if it is not. Here, $B$ can contain both monetary (paid by the firm) and non-monetary elements such as peer-recognition, career concerns or personal satisfaction. We will discuss both these possibilities below. The RU is wealth and credit constrained, and a possible monetary bonus must therefore be non-negative. The RU can ensure itself a non-negative payoff by choosing $e_{R}=0$, which is greater than its outside option. The RU maximizes its utility, which is given by the difference between the expected reward and the cost of creative effort.

\subsection{The production unit}

The PU expends two types of effort: production effort and unobservable defensive effort. The production effort is indispensable for running the technology. The PU receives a payoff normalized to zero as compensation for the production effort. The defensive effort, $e_{P}$, enhances the performance of the existing technology. We have in mind changes in the layout of

${ }^{4}$ As we explain later, it is straightforward to extent the model to include some degree of overlapping between departments. 
production facilities, re-engineering of processes, cost reductions obtained through marginal innovations, elimination of inefficiencies, changes in the design of the products which bring about cost savings or quality improvements, and so on. The defensive effort increases the payoff of the existing technology by $\Delta_{P}=e_{P}$. The total value of the existing technology is therefore $\Delta_{P}$. Such effort does not come for free, and the PU incurs a cost of $c\left(e_{P}\right)=e_{P}$. We call the effort defensive, because the PU expends it only when threatened by a new technology. The reason is that the PU has made technology-specific investments in the existing technology such as mastering it, learning how to deal with break downs, establishing routines and rules, etc. A change of technology forces the PU to reinvest in order to be able to produce. The firm can partially compensate such costs through training programs, monetary incentives and other policies. However, totally offsetting the inconveniencies of change might be hard. ${ }^{5}$ In particular, we assume that the introduction of a new technology imposes a cost of $F$ on the PU. Faced with the potential threat of a new technology developed by the RU, the PU is thus willing to exert effort to improve the existing technology, thereby reducing the likelihood that the new technology is adopted. Put differently, the PU tries to resist change. As an alternative to resisting change, the PU can leave the firm. We assume that this option bears a cost of $K>0$. $K$ can be interpreted as relocation costs, search costs, reputation concerns, risk of being unemployed or simply quasi-rents that are lost if the PU moves to another firm. We start by considering non-monetary incentives only (Section 3) but introduce monetary incentives later on (Section 5). All wages to the PU must be non-negative due to wealth and credit constraints. The PU maximizes its expected utility, which is equivalent to maximizing the total reward if the current technology is kept, i.e. the avoided cost of change plus a possible monetary bonus, minus the cost of the defensive effort (provided that this is a better option than leaving the firm).

\subsection{The management unit}

The last building block of our firm is the MU whose aim is to maximize firm profits. We assume that the firm is able to implement at most one technology, either the existing technology or the new one. There are several reasons why this might be the case. First, the two technologies might produce exactly the same product. Using both would therefore lead to inefficient duplication of costs. Second, the two technologies might depend on different organizational routines, and nurturing both of them would generate incompatibilities. Finally, the technologies might compete for the use of scarce, complementary resources such as managerial talents, dedicated sales forces, financial resources, etc. Hence, after observing the technologies proposed by the two departments, the MU decides either to continue with the existing (improved) technology or to implement the new technology, in which case the PU has to adapt to the new course of actions. Another important choice of the MU concerns the contracts offered to the two departments. The profits of the firm consist of the payoffs from the technology chosen minus all potential payments as compensation or monetary rewards.

\subsection{Timing}

If feasible, the MU chooses the reward structure. Then, the RU expends creative effort to generate a new technology. Simultaneously, the PU expends defensive effort to improve the performance of the existing technology. After uncertainty is resolved, the MU takes a decision about which technology to use. At the end of the game, payoffs are realized.

\section{Solution of the basic model}

To grasp the intuition and understand the key properties of our framework, we solve the model in its simplest version. The robustness of the key properties is discussed later on. We assume here that the MU cannot use monetary instruments to reward the departments. Then, the reward to the PU for maintaining the current technology is the adjustment cost, $F$, that it would have had to bear if the new technology had been introduced. The reward, $B$, to the RU captures non-monetary benefits from having its innovation implemented. What we have in mind here are benefits such as personal satisfaction, career concerns, internal recognition and status that motivate the RU but do not represent an expense for the firm. ${ }^{6}$ We will also assume that $K \geq p F$, which implies that the PU will never use the option to leave the firm.

We solve the game starting from the last stage in which the MU makes a decision about the technologies. Suppose that the RU has developed a new technology. The MU will reject the technology proposed by the RU if $\Delta_{P}=e_{P}>\gamma e_{R}=\Delta_{R}$, whereas it will abandon the existing technology if $\Delta_{P}<\Delta_{R}$. This selection rule for the technology is extremely simple and only requires the MU to make ordinal comparisons among alternatives. ${ }^{7}$ Both the RU and the PU exert efforts in order to influence the MU's decision in their respective interest. This competition between departments can be conceived as a contest with exogenously given different prizes for the contestants. As tie-breaking rule, we assume that if $\Delta_{P}=\Delta_{R}$ the MU chooses the technology of the dominant department, i.e. the department with the highest willingness to invest in the contest. This assumption

\footnotetext{
5 As we discussed in the introduction, the cost of change for the PU should be interpreted broadly to include also psychological factors.

6 Stern (2004) shows that scientists are willing to give up some monetary rewards in exchange for the possibility to work on their preferred research agenda.

7 In addition, different selection rules based on cardinal comparisons among alternatives suffer from commitment problems since, although possibly profit enhancing ex ante, they imply inefficient decisions ex post.
} 
is commonly made in the contest literature (see, for instance, Che and Gale, 2003, p. 653). It is of a similar nature to the assumption that guarantees the existence of a pure strategy equilibrium in a game of Bertrand competition with homogenous products and asymmetric costs.

We distinguish two cases: $F>\gamma B$ and $F<\gamma B$. In the first case the PU would win if both departments invested the full value of their prize into the contest. We will say that the PU "dominates" in this case. It corresponds, e.g., to the situation where inertial forces inside the firm are very strong and production workers and engineers are very adverse to change $(F$ large), i.e. there is a strong resistance to change. The researchers are not or cannot be strongly motivated ( $B$ low), or their creative effort maps very poorly into valuable technology ( $\gamma$ low). In the second case the RU dominates, i.e. it would win if both departments invested the full value of their prize into the contest. This corresponds to a firm with very flexible human capital in its production department that does not fear change $(F$ low). It is also a firm with highly motivated and capable researchers ( $B$ high and $\gamma$ low).

Before finding the equilibrium of the contest, we establish the following result.

Lemma 1. There is no equilibrium in pure strategies.

Intuitive proof. Since the new technology only materializes with probability $p$, the maximum amount of effort that the PU and the RU are willing to exert are $p F$ and $p B$, respectively. Consider the case in which $F>\gamma B$. The other case is symmetric. For any $p B \gamma / 2 F$, the PU is willing to make a defensive effort such that the MU's decision is tilted in its favor. If it chooses such an effort, the best response of the RU is to exert no creative effort. However, the best response to $p(1-F / 2 B \gamma)$ is $F$ given the tie-breaking rule assumed. This is still not an equilibrium because the RU can do better by exerting a creative effort just large enough to win the contest. As this circular argument suggests, no equilibrium in pure strategies exists.

Lemma 1 is a standard result in the contest literature (Taylor, 1997; Che and Gale, 2003). A potential avenue to rescue a pure strategy equilibrium is to make the relationship between the efforts of the contestants and the value of their technology less deterministic. ${ }^{8}$ For instance, one could assume that $\alpha$ and $\Delta_{P}$ are stochastic variables whose distributions depend on $e_{R}$ and $e_{P}$, respectively, and that the effort cost functions are convex. Although this formulation would deliver a pure strategy equilibrium, it turns out to be much harder to handle analytically. Thus, the literature on contests has broadly resorted to mixed strategy equilibria that are much easier to solve in explicit form (Che and Gale, 2003; Burguet and Che, 2004; Konrad, 2006). Since the solution allows a very intuitive interpretation as well, we have chosen to follow in this tradition.

Lemma 2 states the mixed strategy equilibrium for the case where the RU dominates the contest, $F<\gamma B$. In the proof in Appendix A we derive the equilibrium in some detail to illustrate how it is constructed. Hillman and Riley (1989) show that the equilibrium reported here is in fact the unique equilibrium.

Lemma $2(F<\gamma B$ : the RU dominates). In equilibrium the $P U$ randomizes according to the distribution function $G\left(e_{P}\right)=1-(F / \gamma B)+\left(e_{P} / p \gamma B\right)$ for all $e_{P} \in[0, p F]$ and the $R U$ randomizes according to the distribution function $H\left(e_{R}\right)=\gamma e_{R} / p_{F}$ for all $e_{R} \in[0,(p F / \gamma)]$. The expected payoffs for the $P U$, the $R U$ and the firm are respectively: $U_{P}=-p F, U_{R}=p(B-(F / \gamma))$, and $\Pi=(p F / \gamma B)(F(3-2 p)+3 \gamma p B / 6)$.

The next lemma summarizes the equilibrium outcome for the case where the PU dominates, $F>\gamma B$. The equilibria of all the contests we present in the rest of paper are derived using the method illustrated in the proof of Lemma 2 . For this reason, we present the equilibrium strategies, often in Appendix A, but leave out the algebra. Details are available from the authors upon request.

Lemma $3\left(F>\gamma B\right.$ : the PU dominates). In equilibrium the PU randomizes according to $G\left(e_{P}\right)=\left(e_{P} / p \gamma B\right)$ for all $e_{P} \in[0, p \gamma B]$ and the $R U$ randomizes according to $H\left(e_{R}\right)=1-(\gamma B / F)+\left(\gamma e_{R} / p_{F}\right)$ for all $e_{R} \in[0, p B]$. The expected payoffs for the PU, the $R U$, and the firm are respectively: $U_{P}=-p \gamma B, U_{R}=0$, and $\Pi=(B / F)(\gamma P(3 F+\gamma p B / 6)$.

The following remarks describe and compare the equilibrium outcomes for different values of the exogenous parameters.

Remark 1 (Expected efforts). The expected creative effort is $B^{2} p \gamma / 2 F$ if $F>\gamma B$ and $F p / 2 \gamma$ if $F<\gamma B$, whereas the expected defensive effort is $B p \gamma / 2$ if $F>\gamma B$ and $F^{2} p / 2 B \gamma$ if $F<\gamma B$.

Remark 2 (Comparative statics). When the RU dominates, the expected creative effort is increasing in $F$ and decreasing in $\gamma$, whereas the expected defensive effort is increasing in $F$ and decreasing in $\gamma$ and $B$. Expected profits are increasing in $F$ and decreasing in $\gamma$ and $B$. When the PU dominates, the expected creative effort is increasing in $B$ and $\gamma$ and decreasing in $F$, whereas the expected defensive effort is increasing in $B$ and $\gamma$. Expected profits are increasing in $B$ and $\gamma$ and decreasing in F. Finally, expected efforts as well as expected profits are always increasing in the probability that the new technology is developed, $p$.

To interpret these comparative static results one should bear in mind that the efforts exerted by the two departments are aimed at influencing the MU's decision between the existing and the new technology. First, it is obvious that the efforts

\footnotetext{
${ }^{8}$ Another alternative is to use a contest function to determine the winner. Here, the probability to win the prize increases with a contestant's effort and decreases with the rival's effort in a continuous manner. We have preferred not to resort to such a function because it leaves unspecified the decision process, which plays an important role in our story, and it requires further assumptions on how efforts map into profits.
} 
of the PU and the RU are (weakly) increasing in their respective rewards, $F$ and $B$. Second, it is interesting to notice that a larger $F$ does not necessarily mean less profits, as one might have expected given that $F$ parameterizes resistance to change. ${ }^{9}$ In fact, when the RU dominates, a larger $F$ implies that both departments exert more effort and hence profits are higher. ${ }^{10}$ More in general, these comparative statics suggest that the firm always prefers to maintain a balance of powers between the RU and the PU. The intensity of competition between the departments is (inversely) measured by the difference in their strengths, $|F-\gamma B|$, and it is maximized when the departments are equally strong, $F=\gamma B$. These arguments are summarized in the following proposition.

Proposition 1 (Principle of balanced competition). The firm benefits if the relative strength of the two departments is balanced.

The principle of balanced competition is perhaps best understood using an analogy to a track race. A weak runner will not spend a lot of energy racing against a much faster competitor as the chance of winning the race is low. The slow pace of the weak runner, in turn, slows down the strong runner. After all, there is no reason to waste energy by running fast when this is not needed to win the race. In order to make runners perform their best, they should thus be matched against a competitor of equal strength. This is the same basic idea underlying the result of Proposition 1.

Some issues related to this principle deserve discussion. First, we study competition in technologies, but Proposition 1 applies more broadly to competitions inside the firm. Inderst and Laux (2005), e.g., analyze how competition for scarce internal funds can stimulate innovation. They find, in line with Proposition 1, that the positive effect of competition on innovation is strongest when the departments are equally strong.

Second, the intensity of interdepartmental competition is a source of heterogeneity across firms. Firms with more intense, balanced competition perform better in our model. This finding is consistent with some of the empirical findings in the NPD literature, which have shown a positive relationship between conflicts and innovation performance (Ginn and Rubenstein, 1986; Dyer and Song, 1998; Xie et al., 1998).

Third, as explained in Section 2, we have, for pedagogical reasons, kept the interests of our two departments fully orthogonal. However, it is likely that there exists a certain degree of overlap between production and R\&D. This might occur both because in smaller companies the separation between departments tends to be blurred and because the management tries to stimulate collaboration and interaction between functions. One way to capture such an overlap is by assuming that each department shares part of the reward, or loss, of the other department. To model this notion, suppose that each department puts weight $1-\varphi$ on its own payoff and weight $\varphi$ on the payoff of the other department, $0 \leq \varphi \leq 1 / 2$. The model can be analyzed as above by simply replacing the reward to the PU and the RU by $\tilde{F}=(1-\varphi) F-\varphi B$ and $\widetilde{B}=(1-\varphi) B-\varphi F$, respectively. Formulated in this way, an increased overlap (greater value of $\varphi$ ) reduces the stakes of two departments; an effect pushing towards lower efforts and profits. At the same time, the degree of overlap affects the relative strength of the two departments. If the PU dominates, an increased overlap weakens the RU even further. Therefore, applying the logic of Proposition 1, an increased overlap results (unambiguously) in lower efforts and profits. However, if the RU dominates, an increased overlap tends to equalize the strength of the departments. As balance spurs efforts, the total effect of increased overlap on profits is a priori unclear and depends on the specific values of the parameters.

Finally, competition between departments might entail several negative effects that we do not account for in our framework. For example, the development of a new technology might require a strict collaboration between production and R\&D where both departments benefit from reciprocal feedback. Strong competition might hamper such collaboration. Leveraging resistance to change might therefore require firms to develop conflict management strategies or conflict-handling mechanisms (e.g., Dyer and Song, 1998; Xie et al., 1998), which can be time and energy consuming. Strong internal competition might also generate unproductive influence activities (Milgrom and Roberts, 1988) that might call for bureaucratic rules limiting managerial discretion (Milgrom, 1988). Following the general idea that internal competition can have undesirable side effects, which require an organizational response, Section 4 analyzes a situation in which too tough internal competition leads to a distortion in the RU's choice of the research trajectory. We study then how this problem can be ameliorated with an appropriate organizational design.

\subsection{Exploitation versus exploration}

The principle of balanced competition is reminiscent of the suggestion by organizational theorists that the firm should pursue a balance between the exploration of new alternatives and the exploitation of current capabilities (Levinthal and March, 1993; March, 1991; Rivkin and Siggelkow, 2003). As Levinthal and March (1993) put it, “...the basic problem confronting an organization is to engage in sufficient exploitation to ensure its current viability and, at the same time, to devote enough energy to exploration to ensure its future viability".

However, exploitation and exploration are in constant tension. In fact, adaptation to existing environmental demands may foster structural inertia and reduce a firm's capacity to adapt to future environmental changes and new opportunities. In other words, a firm that invests in augmenting its current capabilities and maintaining its current focus might perform rather

\footnotetext{
${ }^{9}$ By the same argument, having a more motivated R\&D department might not always be profit enhancing.

${ }^{10}$ The probability of the RU winning the contest is $p B \gamma / 2 F$ when PU dominates and $p(1-F /(2 B \gamma))$ otherwise. Thus, the expected probability of observing a change in the technology is still decreasing in $F$.
} 
poorly in generating ideas that are outside its core capabilities. Our framework can also handle this possibility, and provide a different, incentive-based explanation of the well-researched tension between exploitative and explorative activities.

Assume that there is a previous period $(t=0)$ before the very same game described above $(t=1)$. In period 0 the firm uses the standard technology. This activity generates profits $\pi_{0}(\alpha)$ where $\alpha$ measures the degree of exploitation. By exploiting the current technology, the MU takes actions that make the production and distribution more efficient, eliminate slacks, routinize activities, and enhance specialization and expertise. Hence, we assume that $\partial \pi_{0}(\alpha) / \partial \alpha>0$. The cost of pushing up the exploitation of the standard technology in period 0 is $C(\alpha)$. Here, $C(\alpha)$ is assumed to be sufficiently convex to ensure that the firm's problem is concave in $\alpha .^{11}$

In period 1 the PU can improve the standard technology as before. Thus, the improvements are on top of $\pi_{0}(\alpha)$. The more the firm invests in the standard technology in period 0 the stronger the PU is in period 1 . For simplicity, we assume that $p=1$. Also, let $\gamma B-\pi_{0}(\alpha)>0$ in the relevant range, otherwise the best strategy for the RU is always to exert zero creative effort.

The following lemma reports the expected period 1 profits as a function of $\alpha$ and $\pi_{0}(\alpha)$.

Lemma 4. If the PU dominates $\left(F+\pi_{0}(\alpha)>\gamma B\right)$, then

$$
\pi_{1}(\alpha)=\frac{\left(B \gamma-\pi_{0}(\alpha)\right)\left(B \gamma(3 F+B \gamma)+(3 F-2 B \gamma) \pi_{0}(\alpha)+\pi_{0}(\alpha)^{2}\right)}{6 B F \gamma}
$$

and $\partial \pi_{1}(\alpha) / \partial \alpha<0$. If instead the RU dominates $\left(F+\pi_{0}(\alpha)<\gamma B\right)$, then

$$
\pi_{1}(\alpha)=\frac{F^{2}+3 B F \gamma-3 F \pi_{0}(\alpha)+12 B \gamma \pi_{0}(\alpha)}{6 B \gamma},
$$

and $\partial \pi_{1}(\alpha) / \partial \alpha>0$.

We now turn to the firm's optimal choice of $\alpha$ in period 0 .

Proposition 2. Let a myopic firm be a firm that maximizes profits period by period. If a myopic firm in period 0 chooses a level of $\alpha$ such that the PU dominates in period 1, then a fully rational, forward-looking firm invests less in the standard technology than a myopic one. However, if a myopic firm in period 0 chooses a level of $\alpha$ such that the RU dominates in period 1, then a fully rational, forward-looking firm invests more in the standard technology than a myopic one.

Greater investment in exploiting the standard technology makes the PU stronger. Indeed, it becomes more costly for the RU to produce enough creative effort to change the status-quo. Put differently, greater exploitation tilts the contest between the RU and the PU in favor of the latter. As long as the PU is already strong and has an advantage in the contest, exploitation makes the competition between the two departments even more unbalanced, so it erodes incentives to exert efforts and reduces profits in period 1 . For this reason, a forward-looking firm would invest less in the standard technology than a myopic firm that only considers period 0 profits when choosing the optimal degree of exploitation. This corresponds well to the notion that exploiting the current technology may hinder the exploration of future opportunities. More broadly, this finding suggests that large established firms, with sunk investments in the current technology and rather inflexible organizations geared at capturing the benefits of economies of scale, find it difficult to explore new opportunities and reinvent themselves. Nevertheless, our model suggests that this is only a part of the story. When the RU is the strongest department, for instance because the firm is operating in a fast developing technological area, further exploitation helps making the competition between the two departments tougher and increases both explorative activities and expected profits.

\section{The skunk works model of innovation}

The outcome of the innovation process depends not only on the intensity of the creative effort, but also on the locus of search. Often researchers have the freedom to choose among an array of research trajectories that encompass different levels of uncertainty, different types of potential innovations, different knowledge bases, different technological competences, among other features. Most importantly from our perspective, while some of these research trajectories, if successful, might lead to important adaptation costs for the PU (large $F$ ), others might instead come at small or no adaptation costs $(F \cong 0$ ). Indeed, some research trajectories are more probable to deliver radical innovations, while other trajectories are more likely to lead to incremental innovations. Radical innovations are based on a new set of routines and expertise. Incremental innovations are based on existing routines and expertise (Henderson, 1993). ${ }^{12}$

Not surprisingly, a research trajectory which might lead to radical innovations (henceforth, a radical trajectory) is likely to meet stronger resistance from the PU (Ginn and Rubenstein, 1986). Indeed, Gilbert (2006) argues that the organizational rigidity increases in the level of threat perceived by the organization. To avoid a costly internal contest, the RU might thus turn to a research trajectory that produces incremental innovations (henceforth, an incremental trajectory). Hence, although

\footnotetext{
${ }^{11}$ In industries where learning-by-doing is important $\alpha$ could be thought of representing the period 0 quantity produced. Higher production in period 0 reduces production costs in period 1 and makes the current technology more profitable.

12 In the organization literature these two kinds of innovations are often referred to as competence destroying and competence enhancing innovations (Tushman and Anderson, 1986).
} 
the competition between the PU and the RU acts as an incentive mechanism, it might also produce a distortion towards less profitable, incremental trajectories.

To stimulate radical innovations, researchers are often isolated from the influence of the rest of the organization. This has become known as the skunk works model of innovation. The skunk works model was, e.g., the organizational design followed by IBM to nurture the by then revolutionary PC (Roberts, 2004), by Ericsson Mobile Communications to develop the Bluetooth technology (Nobelius, 2000), and it is employed by many large innovative firms, such as Intel, HP and Apple, to develop potential breakthroughs.

The skunk works model is claimed to bring several advantages. Echoing the discussion on myopia in organizational learning (March, 1991; Levinthal and March, 1993), it gives researchers the necessary autonomy, independence and freedom to escape the established lines of thought and to produce novel ideas; see, also, Christensen (1997). Closer to the argument of this paper, it can also help to overcome the resistance that radical innovations meet inside the organization. ${ }^{13}$ In the following, we explore the latter advantage using an extension of the basic model developed in Sections 2 and 3.

\subsection{Setup and assumptions}

Let us assume that there are two possible research trajectories, an incremental trajectory and a radical trajectory. The RU chooses the research trajectory before the game analyzed in Section 3 starts.

Assumption 1. The characteristics of the two trajectories are:

Incremental trajectory:

$$
F_{I}=0, \quad p_{I}=1, \quad \gamma_{I}=1, \quad B_{I}=B>0
$$

Radical trajectory:

$$
F_{R}>F_{I}, \quad p_{R}=p<1, \quad \gamma_{R}=\gamma>1, \quad B_{R}=\rho B \quad \text { with } \rho>1 .
$$

Assumption 2. The RU dominates when the incremental trajectory is chosen, i.e. $B>F_{I}$.

Assumption 1 makes operational the idea of different research trajectories. The incremental trajectory leads to innovation with certainty. The innovation builds on the current competences and expertise, so it results in smaller adaptation costs for the PU. Nevertheless, for the RU it is not a particularly "exciting" trajectory, and the reward from having the new technology implemented is lower. Instead, the radical trajectory is riskier, imposes larger adaptation costs upon the PU, but implies a higher potential reward for the RU. Assumption 2 and Lemma 2 imply that the RU is guaranteed a positive expected payoff if it chooses the incremental trajectory in equilibrium, i.e. $U_{R}=B-F_{I}>0$. This is more than plausible as the resistance exerted by the PU is low. In the limit for $F_{I}=0$, Assumption 2 is always satisfied.

Finally, to make the problem interesting, we assume that if the PU observes the choice of the trajectory and can react to it, the RU chooses the incremental trajectory rather than the radical one to avoid a costly internal contest with the PU. The cost of internal competition is thus sufficiently high to potentially influence the choice of the research trajectory. From Lemmata 2 and 3 it follows that this is the case if the following condition holds:

\section{Assumption 3.}

$$
B-F_{I}>\operatorname{Max}\left\{0, p\left(\rho B-\frac{F_{R}}{\gamma}\right)\right\} .
$$

Below we shall investigate whether the firm can improve its expected profits by isolating the RU and creating a skunk works model of innovation. The crucial difference between having the RU integrated in the firm and the skunk works model is the amount of information that the PU receives about the RU's actions. In particular, we assume that the PU observes the choice of research trajectory if the RU is integrated in the firm but not if it is isolated. From a game theoretic point of view, the difference between an integrated innovation model and a skunk works model boils down to the timing of the game. In the integrated model, analyzed so far, the research trajectory is chosen (and observed) before defensive and creative efforts

\footnotetext{
13 The Aurora project set up by Teradyne in the mid-1990s is exemplar of this situation. Teradyne was the market leader (with about $22 \%$ of the world market) in automatic test equipment used in the production of semiconductors. Teradyne employed a technology based on UNIX operating system software, and was trying to shift to the CMOS technology based on Windows NT. In order to overcome the very high organizational resistance to this change, the company decided to create an independent unit, called the Aurora project, that had the autonomy and resources to work on the new technology (Bower, 2005).
} 
are exerted. In the skunk works model the choices of research trajectory and efforts are all simultaneous. ${ }^{14}$ For simplicity, we focus on pure strategies in the choice of the research trajectory.

The timing of the game is as follows. At $t=1$ the MU decides how to organize innovation activity by choosing between an integrated model and the skunk works model. At $t=2$ the RU chooses which research trajectory to focus on, radical or incremental. At $t=3$ the two departments simultaneously exert effort. Then, in case of the radical trajectory, nature determines whether the new technology is a success or a failure. At $t=4$ the MU observes the outcome of the innovation process and decides whether to adopt the new technology. Finally, at $t=5$ all payoffs are realized.

\subsection{The equilibrium analysis}

The first step of the analysis is to determine the conditions under which the MU prefers that the RU pursues the radical trajectory.

Lemma 5. The radical trajectory results in higher profits for the firm than the incremental trajectory if (and only if) the following condition holds:

$$
\Pi_{R}=\operatorname{Min}\left\{\frac{B_{R}}{F_{R}} \frac{\gamma p\left(3 F_{R}+\gamma p B_{R}\right)}{6}, \frac{p F_{R}}{\gamma B_{R}} \frac{F_{R}(3-2 p)+3 \gamma p B_{R}}{6}\right\}>\Pi_{I}=\frac{F_{I}}{\gamma B_{I}} \frac{F_{I}+3 \gamma B_{I}}{6}
$$

where $\Pi_{j}$ is the profit when trajectory $j$ is chosen, $j=I, R$.

Two conditions must be fulfilled for the radical trajectory to be more profitable than the incremental one. First, the stakes of the PU and RU must be greater for the radical than for the incremental trajectory, which requires sufficiently high values of $p, F_{R}$, and $\rho$. High stakes translate into high expected efforts and profits (Lemmata 2 and 3 ). Second, the competition between the two departments if the radical trajectory is chosen must be sufficiently balanced relative to the incremental trajectory (Proposition 1). We shall look at a numerical example below that illustrates these conditions.

There is no doubt that isolating researchers in a skunk works can have strong motivational effects. The researchers might identify themselves with the project and feel obliged to deliver a radical, breakthrough innovation; perhaps even to the extent of disregarding their own interests. The effect of such a perceived obligation can be captured in the model by assuming that the skunk works model of innovation implies the RU's commitment to the radical trajectory. Thus, given Assumption 3, the MU implements the skunk works model to change the RU's choice of trajectory if the condition in Lemma 5 is fulfilled. ${ }^{15}$

Let us turn to the other extreme case where the skunk works model has no commitment effects. The RU behaves here strategically and chooses the trajectory that maximizes its payoff given the equilibrium behaviour of the PU. The next proposition summarizes the equilibrium outcome for this case.

Proposition 3. Assume that $p \rho>1$, i.e. the expected reward to the $R U$ is larger in case of a radical trajectory, and that the $R U$ chooses the payoff maximizing trajectory given the equilibrium behaviour of the PU. Then, (i) the RU chooses the radical trajectory under the skunk works model of innovation and the incremental trajectory under the integrated model of innovation, and (ii) the MU implements the skunk works model of innovation if (and only if) the condition in Lemma $5, \Pi_{R}>\Pi_{I}$, is fulfilled.

Proposition 3 shows that by implementing a skunk works model the firm can make the radical trajectory the equilibrium outcome of the game when this trajectory is sufficiently attractive for the RU. By contrast, Assumption 2 implies that this is never the equilibrium outcome under the integrated innovation model. The intuition behind this finding is the following: in the integrated innovation model, the PU observes the choice of the trajectory. The radical trajectory is therefore unattractive for the RU, because it results in strong defensive effort from the PU. In the skunk works model, on the other hand, the PU does not observe the trajectory chosen. Hence, if the radical trajectory is sufficiently attractive for the RU, the choice of the incremental trajectory cannot be sustained as an equilibrium outcome. The RU would deviate to the radical trajectory in such an equilibrium because it could do so without triggering additional defensive effort by the non-suspecting PU. We show in the proof of Proposition 3 that the skunk works model instead results in an equilibrium where the RU chooses the radical trajectory. Of course, this is expected by the PU, and the two departments exert therefore high effort in equilibrium.

Loosely speaking, in the integrated model the PU and RU can "collude" on the incremental trajectory, an outcome they both prefer vis-à-vis an equilibrium where the radical trajectory is chosen, because the PU punishes a deviation to the radical trajectory by exerting a high amount of defensive effort. Instead, in the skunk works model of innovation the collusion cannot be sustained, because the PU does not observe such a deviation.

Fig. 1 illustrates the equilibrium choice of the innovation model for a numerical example. The two $\Pi_{I}=\Pi_{R}$-curves identify the loci for which the MU is indifferent between the incremental and the radical trajectory. The north-east area of the two curves corresponds to the parameter constellation for which the radical trajectory generates more expected profits. Here, as discussed above, the stakes are high for the two units if the radical trajectory is chosen (high values of $F_{R}$ and $\rho$ ) and the competition is relatively balanced (close to the $F_{R}=\gamma \rho B$-line). If the implementation of the skunk works model implies

\footnotetext{
14 The research trajectory is chosen before the creative effort, but these two choices are observed simultaneously by the PU.

15 If the MU has to compensate the RU for accepting to move to the skunk works facility, this must be subtracted from the expected profits of the radical trajectory, $\Pi_{\mathrm{R}}$, in Lemma 5 .
} 


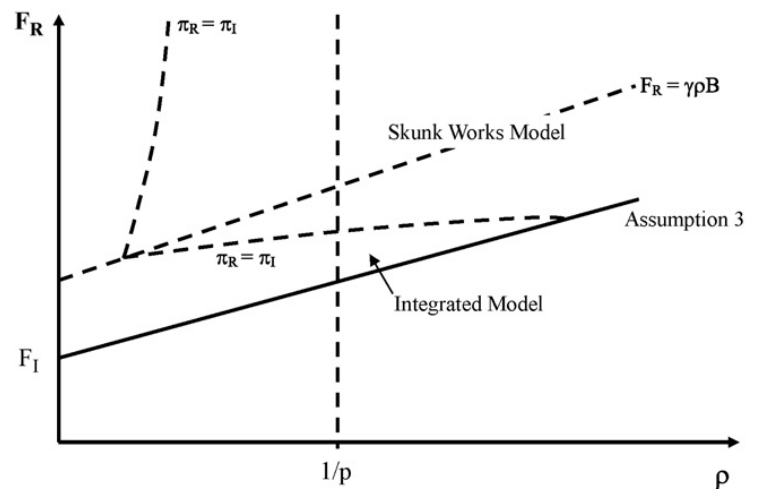

Fig. 1. The equilibrium choice of the innovation model in a specific example $\left(B=0.5, p=0.5, F_{l}=0.4, \gamma=1.2\right)$. Assumption 3 is satisfied above the line with this legend. When the radical trajectory is chosen the PU dominates above the $F_{R}=\gamma \rho B$-line and the RU dominates below. The skunk works model changes the equilibrium outcome from the incremental to the radical trajectory to the right of the line $\rho=1 / p$. The radical trajectory results in higher profits than the incremental trajectory north-east of the two $\Pi_{R}=\Pi_{I}-$ curves.

commitment to the radical trajectory, then the MU chooses the skunk work model in this area. When the skunks works model has no commitment effects, the interesting part of the figure is to the right of the $\rho=1 / p$-line where the skunk works model induces the RU to switch to the radical trajectory. In this region the MU implements the skunk works model for values of $F_{R}$ and $\rho$ such that $\Pi_{R}>\Pi_{I}$ (Proposition 3). As expected, the lack of commitment to the radical trajectory reduces the parameter space under which the skunk works model of innovation is chosen by the MU.

Summarizing, our analysis implies that the firm can benefit from a skunk works model when resistance to change in case of a radical innovation is particularly strong, and would induce researchers to follow more incremental research trajectories under the integrated model. As also suggested by the examples mentioned above, the skunk works model of innovation is likely to be employed by large bureaucratic corporations or established market leaders within a given technological paradigm, which show very high adaptation costs in case of radical innovations (Tushman and Anderson, 1986; Henderson, 1993; Ghemawat, 1991). The other central insight is that the skunk works model is more likely to be successful when it involves a project that the researchers find more interesting than projects involving the current technology.

Of course, the skunk works model can have several costs that we have ignored in the present formulation for the sake of simplicity. For instance, the skunk works model can increase managing costs, can reduce collaboration between the PU and the RU, or can simply have important set up costs. In addition, several difficulties might arise when the innovation developed at the skunk works facility is integrated back into the parent organization. All these elements should be taken into account and would reduce its profitability.

\section{Monetary incentives}

In this section we generalize the previous analysis by introducing monetary incentives and participation constraints for the PU and the RU. To simplify the analysis, we assume that the RU faces monetary incentives only, whereas the PU is motivated by a combination of monetary incentives and the cost of change, $F$. The use of monetary incentive schemes provides the MU with better tools to shape the incentives inside the organization. At the same time, the participation constraints force the MU to partly internalize the costs that internal competition imposes on the PU and the RU.

\subsection{Integrated model with monetary incentives}

We follow an incomplete contract approach by assuming that the characteristics of a technology can be observed ex post, in particular its value, but cannot be included in a contract ex ante. ${ }^{16}$ If contracts can be made contingent on the value of the technology, since there is a one-to-one relationship between efforts and values in our model, then the MU would be able to implement any desired effort level without leaving rents to the PU and the RU. Thus, in a world of perfect contracting possibilities the importance of generating incentives through interdepartmental competition disappears. Details are available from the authors upon request.

\footnotetext{
16 In recent years, there has been a heated debate in economics concerning the foundations for this type of contractual incompleteness (e.g., Maskin and Tirole, 1999; Hart and Moore, 1999; Segal, 1999). We would like to note that the assumption that the values of the technologies are perfectly observed ex post is stronger than needed. We have explored an alternative setup where the MU only observes which technology is the most valuable one, but it does not observe the absolute values. This assumption captures the idea that one of the advantages of a contest is that it requires only ordinal comparisons among alternatives. Adopting this alternative assumption comes at a cost in terms of the complexity of the analysis but does not change our results qualitatively.
} 
We assume below that it is either impossible or prohibitively expensive for outsiders to measure the value generated by the technology. This is, e.g., likely to be the case in large diversified firms with many different sources of revenue where it is difficult to verify the exact project cash flow in court. Thus, contracts based on the value of the technology are not feasible. Alternatively, the MU could contract on certain characteristics of the technology such as design and functionality, but we assume that it does not possess the necessary technical expertise to procure technologies in this way. We follow Rotemberg and Saloner $(1995,2000)$ in assuming that the only information available to contract upon is whether the technology proposed by the RU is implemented or not. This can either be thought of as an explicit contract upheld in court or as an implicit contract maintained through reputational concerns.

\subsubsection{The setup}

At the beginning of the game the MU offers a contract to each of the two departments. The contract to the RU consists of a bonus $B$ if the new technology is implemented, $\mathbf{C}_{\mathrm{RU}}=B$. The contract to the PU consists of a bonus $W$ if the current technology is maintained. The net utility resulting from the bonus is not always sufficient to compensate the PU for the cost of change. For this reason, the contract to the PU might also include a fixed wage $\tilde{W}$ to ensure its participation, $\mathbf{C}_{\mathrm{PU}}=(W, \tilde{W})$.

The PU and the RU observe the offers made and calculate the expected payoff from accepting the contract. They accept the contract if and only if the expected payoff is greater than the outside option. If the contracts are accepted, the RU and the PU simultaneously exert efforts. After uncertainty is resolved, the MU chooses the most profitable technology. At the end of the game, wages are paid and profits are realized.

\subsubsection{The optimal contracts}

We solve the game backwards and look first at the MU's choice between the two technologies. Unlike the basic model, the MU takes the bonuses into account because they represent a cost of using the technology in question. The MU chooses the new technology developed by the RU if and only if $\Delta_{P}-W \leq \Delta_{R}-B \Leftrightarrow e_{P}-W<\gamma e_{R}-B$. Hence, the PU dominates the RU in the contest of technologies if and only if $p(F+W)-W \geq p \gamma B-B$.

From the analysis of the basic model, it should be clear that the MU would never offer bonuses such that the RU dominates the internal competition. If so, the MU could reduce $B$ by some small amount, which would both reduce the expected wage bill and increase the expected efforts due to tougher internal competition. We can thus restrict attention to contracts such that the PU weakly dominates the competition.

The following lemma summarizes the analysis of the competition between the PU and the RU.

Lemma 6. Suppose that the $P U$ and the $R U$ have accepted the proposed contracts. Let $p F-(1-p) W \geq(p \gamma-1) B$, such that the $P U$ dominates the internal competition. The expected payoffs of the PU, the $R U$, and the firm are, respectively: $U_{P}=\tilde{W}-(\gamma-1) B$, $U_{R}=0$, and

$$
\Pi(B, W, \tilde{W})= \begin{cases}\frac{(B-W)^{2}(2 B+3 F+W)-3 B p \gamma\left(B^{2}+2 B F+W^{2}\right)+3(B p \gamma)^{2}(F+W)+(B p \gamma)^{3}}{6 B p(F+W) \gamma}-\tilde{W} & \text { if } B>F \\ \frac{B\left((3 p \gamma-6)(F+W)+B p^{2} \gamma^{2}\right)}{6 B p(F+W)}-\tilde{W} & \text { otherwise }\end{cases}
$$

At the first stage of the game, the MU decides which contracts to offer. The MU does not have to worry about the RU rejecting the contract, as the RU can secure itself a payoff of zero by choosing $e_{R}=0$. The PU can avoid the cost of effort by choosing $e_{P}=0$ but not the cost of change. Hence, the contracts $\mathbf{C}_{\mathrm{PU}}$ and $\mathbf{C}_{\mathrm{RU}}$ have to satisfy a voluntary participation constraint $\left(\mathrm{VPC}_{\mathrm{PU}}\right)$ that ensures to the PU an expected payoff greater than or equal to the outside option.

Using the results of Lemma 5, the optimal contracts solve the following program:

$$
\begin{aligned}
& \operatorname{Max}_{(B, W, \tilde{W})} \Pi(B, W, \tilde{W}) \quad(\text { Program of the MU) } \\
& \text { s.t. } \tilde{W}-(p \gamma-1) B \geq-K \quad\left(\mathrm{VCP}_{\mathrm{PU}}\right)
\end{aligned}
$$

The next proposition characterizes the solution to this program.

Proposition 5. Suppose that it is possible to contract upon the implementation of the new technology. Then, the optimal contract to the PU neither includes a fixed wage nor a bonus if the current technology is maintained: $\mathbf{C}_{\mathrm{PU}}=(W, \tilde{W})=(0,0)$. The optimal contract to the RU is as follows: ( $i$ ) If $p F \leq K$, the optimal contract is chosen such that the competition is balanced: $\boldsymbol{C}_{\mathrm{RU}}=B=p F /(p \gamma-1)$. (ii) If $p F>K$, the optimal bonus is chosen such that the participation constraint of the PU binds: $C_{\mathrm{RU}}=B=K /(p \gamma-1)$.

Proposition 5 confirms the principle of balanced competition but with some qualifications. Part (i) shows that if the participation constraint of the PU does not bind, either because the cost of change is low or the outside option is unattractive, the MU will offer contracts that balance the internal competition. However, the MU only offers a monetary bonus to the RU and relies on the non-monetary cost of change $F$ to motivate the PU. The reason is that the PU's effort comes at a higher cost than the value it creates to the firm. Offering a monetary bonus to both departments in order to obtain higher efforts is therefore not profitable. Part (ii) of Proposition 5 concerns the case where a fully balanced conflict would require a fixed wage 
to the PU to ensure that $\mathbf{C}_{\mathrm{PU}}$ is accepted. ${ }^{17}$ Here, the MU uses $B$ to balance the conflict, but only up to the point where the voluntary participation constraint of the PU binds. Increasing $B$ beyond this threshold would make the RU stronger, balance the conflict further, and result in higher efforts. However, the extra cost in terms of higher wages outweighs the expected benefit, and the MU prefers to maintain the competition unbalanced.

We have also performed different robustness checks. As the logic of the arguments is similar, we have preferred to leave out the formal analysis. Details are available from the authors upon request. First, if the defensive effort were sufficiently productive, it would be optimal to offer a monetary bonus to the PU as well. In this case, the optimal contracts balance the internal competition, include a monetary bonus to both departments, and induce one of the departments to exert the maximal possible effort. Second, rather than rewarding the PU for keeping the current technology, the MU could pay a bonus to the PU as a compensation for the change in the technology. ${ }^{18}$ Such a bonus would decrease the PU's strength, thereby balancing the competition and increasing efforts. However, if the participation constraint of the PU does not bind, the optimal way to balance the competition is by increasing the RU's reward for winning rather than compensating the PU for losing. The reason is that stakes of the two departments in the competition are greater, which results in higher efforts. If the participation constraint of the PU binds in the solution, things can be different. Compensating the PU for the change in the technology achieves here two things: it makes the conflict more balanced, and it relaxes the participation constraint of the PU. The latter effect makes it possible for the MU to balance the competition further by increasing $B$ (the reward to the RU) without having to increase the PU's fixed wage as well. Still, as the expected wage bill increases, it depends on the specific values of the parameters whether compensating the PU for change is profitable or not. ${ }^{19}$

\subsection{Skunk works model with monetary incentives}

A thorough analysis of the skunk works model with monetary incentives would require some lengthy and tedious algebra. We thus only discuss informally how the insights developed in Section 4 would change in this setting. For simplicity, we assume that $K \geq p F$, which implies that the PU will never use the option to leave the firm.

First, notice that if the skunk works model comes with the commitment to work on a radical trajectory, then the analysis in Section 5.1 applies mutatis mutandis. The only difference is that the MU compares the profitability of the two trajectories when bonuses are chosen optimally. Second, if there is no commitment, then one needs to distinguish between whether the monetary reward can or cannot be made contingent upon the trajectory chosen (radical vs. incremental). In the case of contingent rewards, the MU can steer the RU onto the radical trajectory by fixing the reward in case of an incremental trajectory equal to 0 , and make the RU slightly dominate the competition in case of a radical trajectory. ${ }^{20}$ The cost of doing this is very small, as the bonus paid to the RU only needs to be an epsilon greater than the optimal bonus that balances the competition (Proposition 5). Thus, the role of the skunk works model disappears.

When the rewards cannot be made contingent upon the trajectory chosen - which we believe is the most plausible situation - the MU cannot use monetary incentives to induce the choice of the radical trajectory. The reason is that the reward is the same on the two trajectories, but the radical trajectory has a lower success probability. Hence, the RU chooses the incremental trajectory for any positive bonus, both in the integrated model and in the skunk works model. Thus, a necessary condition for the skunk works model to work is the presence of non-monetary incentives (personal satisfaction, career concerns, internal recognition and status, taste for research, etc.), which, other things being equal, make the RU's reward larger on the radical trajectory than on the incremental trajectory. If this is the case, then the analysis of Section 4 applies almost unchanged. The only difference is that now the MU can use a monetary reward to make the competition more balanced and thus increase its expected profits.

Summarizing, with monetary incentives the skunk works model of innovation is still a useful solution to achieve a radical trajectory when: (a) it entails commitment; or (b) monetary incentives cannot be made contingent upon the trajectory chosen and the researchers have a strong intrinsic motivation to work on the radical trajectory.

\section{Discussion and conclusions}

When a firm innovates, its organization, or parts of it, needs to undergo some changes to adapt to the new course of actions. This process is likely to entail costs, and often the introduction of an innovation faces some internal resistance. In this paper we have analyzed the case of a large corporation in which an innovation imposes re-adjustment costs upon a production department that, in response to this threat, tries to resist change by making the current technology more valuable to the firm. This situation is modelled as an internal competition between an R\&D department that investigates and proposes new solutions, and a production department that defends the status-quo. We have shown that stronger resistance to change due

\footnotetext{
${ }^{17}$ Notice that the payoff of the PU is decreasing in the strength of the RU.

18 We thank an anonymous referee for suggesting us this possibility.

${ }^{19}$ It can be optimal for the MU to compensate the PU when the PU is strong (high $F$ ), the RU is weak (low $\gamma$ ), and the outside option of the PU is good (low K).

${ }^{20}$ We only focus on the interesting case in which the firm prefers the radical trajectory but the RU chooses the incremental trajectory to avoid costly competition from the PU.
} 
to larger re-adjustment costs is not necessarily a problem for a firm. To the contrary, firms with a capable R\&D department can leverage such resistance to change to foster more valuable innovations as well as larger improvements of the existing technology.

A key insight from our analysis is what we have labelled as the "principle of balanced competition". In fact, we have shown that, other things equal, firms that successfully maintain a balance between the two departments outperform firms where one department largely dominates the other. Balanced internal competition stimulates efforts both from the production department to improve and perfect the actual technology and from the R\&D department to investigate and propose even better solutions.

While the general principle is simple, its proper application requires detailed knowledge of the firm and its environment. We have shown that the strength of the departments depends on many different factors such as the cost of change, the intrinsic motivation of the researchers, the potential of the new technology, the degree of overlap between the departments, etc. It is the combination of these variables that determines the degree of internal competition. This complexity notwithstanding, the principle still provides useful guidance to practitioners. It suggests, for example, that firms that face very strong resistance to change should hire more able researchers, or increase the budget of their R\&D department, to leverage the internal competition further. ${ }^{21}$ This emphasizes the point made above that strong inertial forces are not necessarily a disadvantage for a firm, but can - if properly managed - spur both innovation and performance. Similarly, firms that have a well-trained and flexible production department that embraces rather than resists change should be careful not to strengthen the R\&D department too much, e.g., by offering high-powered monetary incentive schemes.

The principle of balanced competition is similar in spirit to the recommendation by organization scholars that the successful firm should pursue a balance between exploration of new alternatives and exploitation of current capabilities (Levinthal and March, 1993; Rivkin and Siggelkow, 2003). In our model, while the production department is devoted to improve and perfect the actual technology, the R\&D department is in charged with identifying and exploring new opportunities. We contribute to this literature by offering a different, incentive-based view of the tension between exploitative and explorative activities. The traditional argument is that by investing too much in one activity the firm develops routines and accumulates learning that are idiosyncratic to this activity, and that reduces its ability to perform the other activity. We offer here a complementary reason for keeping a balance between these activities: they compete for scarce resources, and such competition generates the highest payoff when it is equally grounded.

Our model deliberately emphasizes the benefits of internal competition and thus the importance of managing such competition in the most efficient way. However, we do not deny that competition between the departments might give rise to costs as well. These costs can take the form of lack of collaboration, failure to establish a corporate culture, influence activities, etc. In the second part of the paper, we address this issue by looking at the potential distortion that the threat of internal competition might generate in the choice of the research trajectory. The problem arises when the R\&D department chooses an incremental trajectory instead of a more profitable radical trajectory to avoid a costly competition with the production department. We show that the firm can restore the incentives to choose a radical trajectory by implementing the so-called "skunk works model" of innovation, which consists of isolating the R\&D department from the rest of the firm. This provides, to the best of our knowledge, the first formal analysis of the skunk works model; an innovation model that has been widely discussed in the business press and extensively applied by firms like IBM, Siemens, Philips and Intel, among others.

Stretching a bit the boundaries of our model, one could argue that re-adjustment costs in the case of radical innovations are especially important for large established firms. Thus, our paper fits well within the organization literature that has analyzed extensively the problems that large established incumbents have in developing and adopting radical innovations that require completely new sets of routines and capabilities (Henderson and Clark, 1990; Henderson, 1993; Ghemawat, 1991). We contribute to this literature by emphasizing that even if established firms might be endowed with the routines and capabilities to cope with radical innovations, the threat of costly internal competition might prevent the R\&D department from exploring more radical research trajectories.

Isolating the researchers in a skunk works might in itself make them try to develop a radical innovation. However, if this is not the case, two important considerations for managers have emerged from our analysis of the skunk works model. First, the key element of the skunk works model is that the information flows between the R\&D department and the rest of the organization are eliminated. This finding implies that secrecy and autonomy are very important for this organizational solution to function properly. If it is possible to infer the type of project on which the R\&D department is working, e.g., from financial accounts or internal memos, our analysis suggests that the advantage of the skunk works model of innovation is lost. Second, our paper shows that in order to induce the R\&D department to choose the radical trajectory, the expected reward should include a sufficiently large non-monetary component. This implies that researchers who are part of a skunk works model must have a taste for radical innovations; that is, they should enjoy working in an experimental, risky, and exciting environment where major breakthroughs could emerge, but where lots of uncertainties are still unsolved. Thus, the selection of the researchers who should belong to the skunk works model is a critical task for the management of the firm and its human resources department.

\footnotetext{
${ }^{21}$ This result is of a similar flavor to early work by Lazear and Rosen (1981) who suggested that workers in a promotion contest should be matched in groups of similar ability.
} 
As a final consideration, our approach has stressed the importance of generating incentives through internal competition when contracting possibilities are either limited or too costly. The complexities and uncertainties of the innovation process make an incomplete contract approach quite reasonable within our context. However, we believe that, except in cases where contracting possibilities are extremely good, the insights of our analysis are still valid and relevant when more contractual solutions are available. The role of monetary rewards is then to top up non-monetary incentives and to balance the competition between the departments.

\section{Acknowledgements}

We would like to thank Ashish Arora, Sandro Brusco, Marco S. Giarratana, Joachim Henkel, Lars Persson, Karl Schlag, and seminar participants at Carnegie Mellon University, Universidad Carlos III de Madrid, Aarhus Business School, Copenhagen Business School, IESE Business School (Barcelona) and the European University Institute (Florence) for helpful comments and suggestions on an earlier draft. Financial support from the Fundación Ramón Areces (A. Fosfuri) is gratefully acknowledged. The usual disclaimer applies.

\section{Appendix A. Proofs of lemmata and propositions}

Proof of Lemma 2. The maximal amount that the RU and the PU would be willing to invest into the contest are $p B$ and $p F$, respectively. Following the argument outlined in the proof of Lemma 1, it can be shown that there does not exist an equilibrium in mixed strategies where the two units randomize among a finite number of effort levels. Consider instead an equilibrium where the two units randomize among an infinite number of effort levels. In particular, the PU randomizes among all $e_{P} \in[0, p F]$ according to the distribution function $G(\cdot)$, and the RU randomizes among all $e_{R} \in[0, p F / \gamma]$ according to the distribution function $H(\cdot)$. Assuming that the RU does not put probability mass on any effort level, which is satisfied in equilibrium, the expected utility of the PU can be written as

$$
U_{P}=p\left(1-H\left(\frac{e_{P}}{\gamma}\right)\right)\left(w-e_{P}-F\right)+\left(1-p\left(1-H\left(\frac{e_{P}}{\gamma}\right)\right)\right)\left(w-e_{P}\right) \Leftrightarrow H\left(e_{R}\right)=\frac{U_{P}-w+p F}{p F}+\frac{\gamma e_{R}}{p F} .
$$

Turning to the RU, we have:

$$
U_{R}=p G\left(\gamma e_{R}\right)\left(B-e_{R}\right)+\left(1-p G\left(\gamma e_{R}\right)\right)\left(-e_{R}\right) \Leftrightarrow G\left(e_{P}\right)=\frac{U_{R}}{p B}+\frac{e_{P}}{p \gamma B} .
$$

Using $G(p F)=1$ and $H(p F / \gamma)=1$, it follows that:

$$
H\left(e_{R}\right)=\frac{\gamma e_{R}}{p F} \text { for all } e_{R} \in\left[0, \frac{p F}{\gamma}\right] \text { and } U_{P}=w-p F, \quad G\left(e_{P}\right)=1-\frac{F}{\gamma B}+\frac{e_{P}}{p \gamma B} \quad \text { for all } e_{P} \in[0, p F] \text { and } U_{R}=p\left(B-\frac{F}{\gamma}\right) \text {. }
$$

Finally, the expected profits of the firm can be written as

$$
E \Pi=\int_{0}^{p F / \gamma}\left\{G\left(\gamma e_{R}\right)\left[\left(p \gamma e_{R}+(1-p) E\left(e_{P} \mid e_{P}<\gamma e_{R}\right)\right]+\left(1-G\left(\gamma e_{R}\right)\right) E\left(e_{P} \mid e_{P}>\gamma e_{R}\right)\right\} h\left(e_{R}\right) d e_{R},\right.
$$

where $E\left(e_{P} \mid e_{P}>\gamma e_{R}\right)=\left(p F+\gamma e_{R} / 2\right), E\left(e_{P} \mid e_{P}<\gamma e_{R}\right)=\left(1 / G\left(\gamma e_{R}\right)\right) \int_{0}^{\gamma e_{R}} e_{P} / p \gamma B d e_{p}$, and $h\left(e_{R}\right)=\gamma / p F$. Simplifying the expression, we obtain the expected profits reported in the lemma. $\square$

Proof of Remark 1. The expected efforts are obtained using the distribution functions reported in Lemmata 2 and 3 and integrating over the relevant intervals.

Proof of Remark 2. The comparative statics follow directly from differentiating the profit expressions in Lemmata 2 and 3 and from the expected efforts reported in Remark 1 . $\square$

Equilibrium Strategies and Proof of Lemma 4. When the PU dominates $\left(F+\pi_{0}(\alpha)>\gamma B\right)$, the PU randomizes according to $G\left(e_{P}\right)=\left(\pi_{0}(\alpha)+e_{P}\right) / \gamma B$ for all $e_{P} \in\left[0, \gamma B-\pi_{0}(\alpha)\right.$. The RU randomizes among $e_{R} \in\{0\} \cup\left[\left(\pi_{0}(\alpha) / \gamma\right), B\right]$ according to $H\left(e_{R}\right)$ where $H\left(e_{R}\right)=1-(\gamma B / F)+\left(\pi_{0}(\alpha) / \gamma\right)$ for all $e_{R} \in\left[0, \pi_{0}(\alpha) / \gamma\right)$ and $H\left(e_{R}\right)=1-(\gamma B / F)+\left(\gamma e_{R} / F\right)$ for all $e_{R} \in\left[\left(\pi_{0}(\alpha) / \gamma\right), B\right]$. When the RU dominates $\left(F+\pi_{0}(\alpha)<\gamma B\right)$, the PU randomizes according to $G\left(e_{P}\right)=1-(F / \gamma B)+\left(e_{P} / \gamma B\right)$ for all $e_{P} \in[0, F]$ and the RU randomizes according to $H\left(e_{R}\right)=\left(\gamma e_{R} / F\right)-\left(\pi_{0}(\alpha) / F\right)$ for all $e_{R} \in\left[\pi_{0}(\alpha) / \gamma,\left(\pi_{0}(\alpha)+F\right) / \gamma\right]$. The expected profits are calculated using the equilibrium strategies reported above. The sign of $\partial \pi_{1}(\alpha) / \partial \alpha$ follows directly from $\partial \pi_{1}(\alpha) / \partial \alpha=\left[\partial \pi_{1}(\alpha) / \partial \pi_{0}(\alpha)\right]\left[\partial \pi_{0}(\alpha) / \partial \alpha\right]$ where $\partial \pi_{0}(\alpha) / \partial \alpha>0$.

Proof of Proposition 2. A myopic firm chooses $\alpha$ to solve $\partial \pi_{0}(\alpha) / \partial \alpha-\partial C(\alpha) / \partial \alpha=0$ whereas a forwarding-looking firm solves $\partial \pi_{0}(\alpha) / \partial \alpha+\partial \pi_{1}(\alpha) / \partial \alpha-\partial C(\alpha) / \partial \alpha=0$. The proof follows then from the concavity of the profit function in $\alpha$ and the sign of $\partial \pi_{1}(\alpha) / \partial \alpha$ as reported in Lemma 4.

Proof of Proposition 3. Consider first part (i). Notice that Assumption 3 implies that the RU chooses the incremental trajectory under the integrated model of innovation. Consider now the skunk works model. Here, there cannot exist an 
equilibrium where the RU chooses the incremental trajectory. In such an equilibrium, the PU randomizes according to $G\left(e_{P}\right)=1-\left(F_{I} / B\right)+\left(e_{P} / B\right)$ for all $e_{P} \in\left[0, F_{I}\right]$ and $U_{R}=\mathrm{G}\left(e_{R}\right) B-e_{R}$. The RU has an incentive to deviate to the radical trajectory that results in an expected utility of $p G\left(\gamma e_{R}\right) \rho B-e_{R}$, which is strictly greater than $G\left(e_{R}\right) B-e_{R}$ for any given $e_{R}$ since $\gamma>1$ (Assumption 1) and $p \rho>1$.

Consider instead an equilibrium where the $\mathrm{RU}$ chooses the radical trajectory. From Lemma 3 we know that when $F_{R}>\gamma \rho B$ the PU randomizes in equilibrium according to $G\left(e_{P}\right)=\left(e_{P} / p \gamma \rho B\right)$ for all $e_{P} \in[0, p \gamma \rho B]$ and $U_{R}=0$. Suppose that the RU would deviate to the incremental trajectory. This would produce an expected utility equal to:

$$
G\left(\gamma e_{R}\right)\left(B-e_{R}\right)+\left(1-G\left(\gamma e_{R}\right)\right)\left(-e_{R}\right)=e_{R}\left(\frac{1}{p \gamma \rho}-1\right),
$$

which is non-positive since $\gamma>1$ and $p \rho>1$. Therefore, the RU has no incentive to deviate. Similarly, when $F_{R}<\gamma \rho B$ the PU randomizes according to $G\left(e_{P}\right)=1-\left(F_{R} / \gamma \rho B\right)+\left(e_{P} / p \gamma \rho B\right)$ for all $e_{P} \in\left[0, p F_{R}\right]$ and $U_{R}=p\left(\rho B-\left(F_{R} / \gamma\right)\right)$. Suppose that the RU would deviate to the incremental trajectory. This would produce an expected utility equal to $B-\left(F_{R} / \gamma \rho\right)+\left(e_{R} / p \rho\right)-e_{R}$. Since $p \rho \gamma>1$, the optimal effort when deviating to the incremental trajectory would therefore be $e_{R}=0$. This would result in an expected utility of $B-F_{R} / \rho \gamma$. It is easy to see that such deviation is not profitable when $p \rho>1$. Hence, for $p \rho>1$ only the radical trajectory can be sustained as an equilibrium outcome of the game.

Consider now part (ii). Given the result of part (i), the MU chooses the skunk works model if and only if the radical trajectory results in higher profits than the incremental trajectory. The result follows. $\square$

Proof of Lemma 5. The Lemma follows directly from the profit functions in Lemmata 2 and 3, noticing that the RU dominates when the incremental trajectory is chosen from Assumption 2 whereas either the RU or the PU can dominate when the radical trajectory is chosen.

Proof of Lemma 6. Suppose that the PU dominates and that $B>W$. Then, the PU randomizes according to $G\left(e_{P}\right)=(B-W+$ $\left.e_{P}\right) / \gamma p B$ for all $e_{P} \in[0,(\gamma p-1) B+W]$ and the RU randomizes according to $H\left(e_{R}\right)=1-(\gamma B /(F+W))+\left(\gamma e_{R} /(p(F+W))\right)$ for all $e_{R} \in\{0\} \cup[(B-W) / \gamma, p B]$.

Suppose instead that the PU dominates but that $B \leq W$. Then, the PU randomizes according to $G\left(e_{P}\right)=\left((B-W)+e_{P}\right) / \gamma p B$ for all $e_{P} \in[W-B,(\gamma p-1) B+W]$ and the RU randomizes according to $H\left(e_{R}\right)=1-(\gamma B /(F+W))+\left(\gamma e_{R} /(p(F+W))\right)$ for all $e_{R} \in[0, p B]$.

The expected profits are calculated as in the proof of Lemma 2, the only difference being that the bonuses are monetary and therefore represent a cost for the firm.

Proof of Proposition 5. We consider two cases, $K \geq p F$ and $K<p F$.

Case I: $K \geq p F$.

The PU can always ensure a payoff of $-p F$ by choosing $e_{P}=0$. Hence, the participation constraint does not bind and $\tilde{W}=0$. The optimal bonuses are such that $B \geq W$ since $\partial \Pi(B, W, 0) / \partial W \leq 0$ for $W>B$. Hence, $B \in[W,(p(F+W)-W) / p \gamma-1]$ where the upper bound on $B$ guarantees that the PU dominates. Notice that this implies that $W \in[0, F /(\gamma-1)$.

Since $\partial^{2} \Pi(B, W, 0) / \partial B^{2}>0$, there are two sets of solutions depending on whether $B=W$ or $B=(p(F+W)-W) /(p \gamma-1)$. Consider first the candidate solutions for which $B=W$. Since $\partial^{2} \Pi(W, W, 0) / \partial W^{2}>0$, the candidate solutions are $B=W=0$ and $B=W=F /(\gamma-1)$.

Consider instead the candidate solutions for which $B=(p(F+W)-W) /(p \gamma-1)$. Here, $\partial^{2} \Pi((p(F+W)-W) /$ $(p \gamma-1), W, 0) / \partial W^{2}>0$. This results in an additional candidate solution, $B=p F /(p \gamma-1)$ and $W=0$ plus the previous candidate solution $B=W=F /(\gamma-1)$.

Finally, comparing the profits of the three candidate solutions, the result reported in the proposition is obtained. $\square$

Case II: $K<p F$.


does not bind for $B \leq K /(p \gamma-1)$. Only the proof for the case $K /(p \gamma-1)<F /(\gamma-1)$ is included, but the proof for the other case is similar. Details are available upon request.

As in Case I, it has to hold that $B \in[W,(p(F+W)-W) /(p \gamma-1)]$ and $W \in[0, F /(\gamma-1)]$. Furthermore, because $\partial^{2} \Pi(B, W, 0) / \partial B^{2}>0$ both for $B>K /(p \gamma-1)$ and $B \leq K /(\mathrm{p} \gamma-1)$, the optimal bonus $B$ is a corner solution.

Consider first $B \in[W, K /(p \gamma-1)]$ where $\tilde{W}=0$. There are two sets of solutions depending on $B=W$ or $B=K /(p \gamma-1)($ as $K /(p \gamma-1)<(p(F+W)-W) /(p \gamma-1)$ in the case considered). Similar to Case I, the candidate solutions for $B=W$ are: $(\mathrm{i})$ $B=W=0$ and (ii) $B=W=K /(p \gamma-1)$. For $B=K /(p \gamma-1)$, it can be shown that $\partial \Pi((K / p \gamma-1), W, 0) / \partial B<0$. Hence, the candidate solution is: (iii) $B=K /(p \gamma-1)$ and $W=0$. Comparing the three candidate solutions, $(\partial \Pi((K /(p \gamma-1)), W, 0)) / \partial B<0$ implies that candidate solution (iii) dominates candidate solution (ii). Furthermore, candidate solution (iii) dominates candidate solution (i), because $\Pi(0,0,0)<\Pi(K /(p \gamma-1), 0,0)$. Hence, the optimal bonuses for $B \in[W, K /(p \gamma-1)]$ are $B=K /(p \gamma-1)$ and $W=0$.

Consider instead $B \in[K /(p \gamma-1),(p,(F+W)-W)(p \gamma-1)]$ where $\tilde{W}=B(\gamma p-1)-K$. For $B=K /(p \gamma-1)$, the relevant candidate solution is again: (i) $B=K /(p \gamma-1)$ and $W=0$. For $B=(p(F+W)-W) /(p \gamma-1),\left(\partial^{2} \Pi((p(F+W)-W)) /\right.$ $(p \gamma-1), W, 0) / \partial W^{2}>0$ implies that the candidate solutions are: (ii) $B=W=F /(\gamma-1)>K /(p \gamma-1)$ and (iii) $B=p F /(p \gamma-1)$ and $W=0$. Here, as $\Pi(K /(p \gamma-1), 0,0)>\Pi(K /(p \gamma-1), K /(p \gamma-1), 0)>\Pi(F /(\gamma-1), F /(\gamma-1), F(\gamma p-1) /(\gamma-1)-K)$, candi- 
date solution (i) dominates candidate solution (ii). Furthermore, as $\partial \Pi(B, 0, B(\gamma p-1)-K) / \partial B<0$ for $B>K /(p \gamma-1)$, candidate solution (i) dominates candidate solution (iii).

Summarizing the two cases, the optimal bonuses are $B=p F /(p \gamma-1)$ and $W=0$ for $K<p F$.

\section{References}

Birkinshaw, J., Lingblad, M., 2005. Intrafirm competition and charter evolution in the multibusiness firm. Organization Science 16, 674-686.

Bower, J.L., 2005. Teradyne: The Aurora Project. Harvard Business School, Case Study \#9-397-114.

Burguet, R., Che, Y.-K., 2004. Competitive procurement with corruption. RAND Journal of Economics 35, 50-68.

Che, Y.-K., Gale, I., 2003. Optimal design of research contests. American Economic Review 93, 646-671.

Christensen, C., 1997. The Innovator's Dilemma: When New Technologies Cause Great Firms to Fail. Harvard Business School Press, Boston, MA.

Dosi, G., 1982. Technological paradigms and technological trajectories. Research Policy 11, 147-162.

Dyer, M., Song, X.M., 1998. Innovation strategy and sanctioned conflict: a new edge in innovation? Journal of Product Innovation Management 15, 505-519.

Foster, R., 1986. Innovation: The Attacker's Advantage. Summit Books, New York.

Ganuza, J.J., Hauk, E., 2006. Allocating ideas: horizontal competition in tournaments. Journal of Economics and Management Strategy 15, 763-787.

Ghemawat, P., 1991. Market incumbency and technological tnertia. Marketing Science 10, 161-171.

Gilbert, C.G., 2006. Change in the presence of residual fit: can competing frames coexist? Organization Science 17, 150-167.

Ginn, M.E., Rubenstein, A.H., 1986. The R\&D production interface: a case study of new product commercialization. Journal of Product Innovation Management $3,158-170$.

Griffin, A., Hauser, J.R., 1996. Integrating R\&D and marketing: a review and analysis of the literature. Journal of Product Innovation Management $13,191-215$.

Hart, O., Moore, J., 1999. Foundations of incomplete contracts. Review of Economic Studies 66, 115-138.

Henderson, R., 1993. Underinvestment and incompetence as responses to radical innovation: evidence from the semiconductor photolithographic alignment equipment industry. RAND Journal of Economics 24, 248-270.

Henderson, R., Clark, K.B., 1990. Architectural innovation: the reconfiguration of existing product technologies and the failure of established firms. Administrative Science Quarterly 35, 9-30.

Hillman, A.L., Riley, J.G., 1989. Politically contestable rents and transfers. Economics and Politics 1, 17-39.

Inderst, R., Laux, C., 2005. Incentives in internal capital markets. RAND Journal of Economics 36, 215-228.

Konrad, K.A., 2006. Silent interests and all-pay auctions. International Journal of Industrial Organization 24, 701-713.

Lazear, E.P., Rosen, S., 1981. Rank-order tournaments as optimum labor contracts. Journal of Political Economy 89, 841-864.

Levinthal, D., March, J., 1993. The myopia of learning. Strategic Management Journal 14, 95-112.

Luo, X., Slotegraaf, J.R., Pan, X., 2006. Cross-functional “coopetition”: the simultaneous role of cooperation and competition within firms. Journal of Marketing $70,67-80$.

March, J., 1991. Exploration and exploitation in organizational learning. Organization Science 2, 71-87.

Maskin, E., Tirole, J., 1999. Unforeseen contingencies and incomplete contracts. Review of Economic Studies 66, 83-114.

Meyer, M., Milgrom, P.R., Roberts, J., 1992. Organizational prospects, influence costs and ownership changes. Journal of Economics and Management Strategy 1, 9-35.

Milgrom, P.R., 1988. Employment contracts, influence activities and efficient organization design. Journal of Political Economy 96, 42-60.

Milgrom, P.R., Roberts, J., 1988. An economic approach to influence activities in organizations. American Journal of Sociology 94, S154-S179.

Morrill, C., 1991. Conflict management, honor, and organizational change. American Journal of Sociology 97, 585-621.

Nelson, R.R., Winter, S.G., 1982. An Evolutionary Theory of Economic Change. Belknap Press/Harvard University Press, Cambridge.

Nobelius, D., 2000. An ambidextrous organization in practice-strategic actions in Ericsson's management of 'Bluetooth'. IMIT Working Paper \#113.

Rivkin, J.W., Siggelkow, N., 2003. Balancing search and stability: interdependencies among elements of organizational design. Management Science 49, $290-311$.

Roberts, J.D., 2004. The Modern Firm. Oxford University Press, Oxford.

Rotemberg, J., Saloner, G., 1995. Overt interfunctional conflict and its reduction through business strategy. RAND Journal of Economics 26, $630-653$.

Rotemberg, J., Saloner, G., 2000. Visionaries, managers and strategic direction. RAND Journal of Economics 31, 693-716.

Schaefer, S., 1998. Influence costs, structural inertia, and organizational change. Journal of Economics and Management Strategy 7, $237-263$.

Segal, I., 1999. Complexity and renegotiation: a foundation for incomplete contracts. Review of Economic Studies 66, 57-82.

Stern, S., 2004. Do scientists pay to be scientists? Management Science 50, 835-853.

Taylor, C., 1997. Digging for golden carrots: an analysis of research tournaments. American Economic Review 85, 872-890.

Tushman, M.L., Anderson, P., 1986. Technological discontinuities and organizational requirements. Administrative Science Quarterly 31, 439-465.

Xie, J., Song, X.M., Stringfellow, A., 1998. Interfunctional conflict, conflict resolution styles, and new product success: a four-culture comparison. Management Science 44, 192-206. 